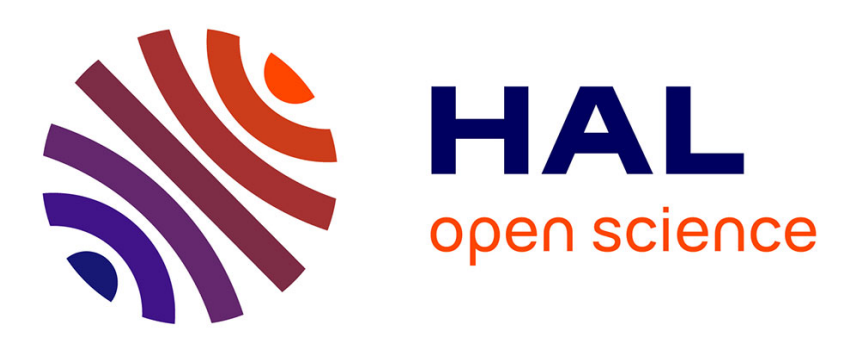

\title{
Topography characterization of sinusoidal surfaces obtained with electrochemical machining
}

Julie Marteau, Karine Anselme, Laurent Pieuchot, Pierre-François Chauvy, Maxence Bigerelle

\section{To cite this version:}

Julie Marteau, Karine Anselme, Laurent Pieuchot, Pierre-François Chauvy, Maxence Bigerelle. Topography characterization of sinusoidal surfaces obtained with electrochemical machining. Surface Topography: Metrology and Properties, 2021, 9 (2), pp.025002. 10.1088/2051-672X/abeae9 . hal03358742

\section{HAL Id: hal-03358742 \\ https://hal.science/hal-03358742}

Submitted on 19 Nov 2021

HAL is a multi-disciplinary open access archive for the deposit and dissemination of scientific research documents, whether they are published or not. The documents may come from teaching and research institutions in France or abroad, or from public or private research centers.
L'archive ouverte pluridisciplinaire HAL, est destinée au dépôt et à la diffusion de documents scientifiques de niveau recherche, publiés ou non, émanant des établissements d'enseignement et de recherche français ou étrangers, des laboratoires publics ou privés. 
Topography characterization of sinusoidal surfaces obtained with electrochemical machining

Julie Marteau ${ }^{1}$, Karine Anselme ${ }^{2}$, Laurent Pieuchot ${ }^{2}$, Pierre-François Chauvy ${ }^{3}$, Maxence Bigerelle ${ }^{4}$,

${ }^{1}$ Sorbonne Université, Université de Technologie de Compiègne, Laboratoire Roberval de Mécanique, FRE UTC-CNRS 2012, Compiègne, France.

${ }^{2}$ Mulhouse Materials Science Institute IS2M - UMR CNRS 7361, Mulhouse, France.

${ }^{3}$ Micropat SA, Côtes-de-Montbenon 30, 1003, Lausanne, Switzerland

${ }^{4}$ Laboratoire d'Automatique, de Mécanique et d'Informatique industrielles et Humaines

LAMIH UMR-CNRS 8201, Université de Valenciennes et du Hainaut Cambrésis, Le Mont

Houy, Valenciennes, France

julie.marteau@utc.fr

\begin{abstract}
The study and understanding of functionality and its link with surface topography requires surfaces that enable us to decouple the examined effect. The sinusoidal function offers an easy solution for the decoupling of amplitude and frequency. However, the corresponding surfaces would require very good characteristics: shape regularity, low waviness and low microroughness. This study thoroughly characterized sinusoidal surface (egg-box shapes) having periods ranging from $30 \mu \mathrm{m}$ to $300 \mu \mathrm{m}$ and peak-to-valley amplitudes comprised between 3 and $30 \mu \mathrm{m}$. The microroughness of the examined surfaces was quantified with the arithmetic mean deviation $S_{a}$ and was found to be around $1 \mathrm{~nm}$ for most examined surfaces. The waviness of the surfaces, which was also quantified with Sa, was lower than $0.15 \mu \mathrm{m}$ for all the surfaces. The relative error computed for the period of the sinusoidal surfaces was lower than $1.3 \%$. Finally, the shape regularity was assessed by comparing the measurements to a mathematical function and the computed average residues were smaller than $0.8 \mu \mathrm{m}$. These characteristics highlighted the very good noise-to-signal ratio of the produced surfaces, which can be used in very different fields (biology, mechanics, optics...) to examine topography effect on functionality (cell adhesion, brightness...).
\end{abstract}

Keywords: sinusoidal, topography, functionality.

\title{
1. Introduction
}

There is currently a growing interest in surface texturing for the improvement of surface functionality. However, the improvement of functionality requires a good understanding of the link between morphology and functionality. It is currently difficult to dissociate the effects of amplitude, frequency and anisotropy on functionality. Tackling this issue requires finding the appropriate surface shape covering classic surface data (i.e. amplitude and frequency ranges of commonly examined phenomena). In our opinion, the best shape to decouple the effects of amplitude and frequency is the sinusoidal function. The sinusoidal function offers an easy modelling of topography using only two independent parameters (amplitude and frequency). It can be seen as an elementary surface having "no frequency artefact" thus offering a perfect 
decomposition into Fourier series. Such qualities facilitate parameter identification in the search for analytical solutions or model fitting. Furthermore, the possibility of having a sinusoidal shape in one direction (corrugated surface) or in two directions (egg-box like surfaces) with fixed amplitude and frequency is of interest for the examination of anisotropy effects.

However, the sinusoidal shape remains very difficult to achieve: the slightest defect will introduce artefacts during the topographical analysis. Several processes can be identified in the literature for the building of sinusoidal surfaces. Song et al. [1] used X-ray lithography on polymers to create corrugated surfaces for the study of the migration of cells. Surface winkling of polymers is often chosen to create corrugated surfaces in polymers: Skedung et al. [2] used this process to examine the tactile perception of textured surfaces while Bukowsky et al. [3] applied it for the investigation of wettability. Similarly, Yang et al. [4] used transfer printing to obtain soft composite films exhibiting corrugation to experimentally validate the mechanics of tension-induced corrugation. Antos et al. [5] proposed to use polymer grating to produce twodimensional sinusoidal surfaces and examined the quality of the sinusoidal shape with spectroscopic ellipsometry. Lu et al. [6] produced sinusoidal grid surfaces by diamondmachining copper roller and then performed a UV-molding technique to replicate the topography on a plane surface. Chen et al. [7] used three-dimensional surface produced with diamond machining to investigate the characteristics of a specially developed tunnelling microscope. Recently, Temmler et al. [8] examined surface structuring by laser remelting using finite element modelling and experimentation. They obtained local topographies having sinusoidal shapes.

These few examples highlight the interest in sinusoidal surfaces in different fields: biology (cell migration [1,9,10], tactile perception [2]), mechanics (wettability [3,6], metrology [7,11], adhesion [12]). Numerous numerical studies are also based on the examination of sinusoidal surfaces. Xie et al. [13] investigated rail head wear. Peng et al. [14] studied peeling behaviour while Declercq et al. [15] used sinusoidal surfaces to examine the diffraction of sound. Thenard et al. [16] used three-dimensional modelling to examine the influence of surface topography on cell motility: sinusoidal parallel grooves were among the tested topographies.

Recently, we manufactured three-dimensional surfaces having very smooth surface and shape accuracy to examine the effect of curvature on cell migration [17]. This paper aims at thoroughly charactering the topography of these surfaces. Then, these surfaces are compared to the surfaces described in the literature and their applications on the study of surface functionality are discussed.

\section{Materials and Methods}

\subsection{Specimens}

The discussed sinusoidal surfaces were created using a two-step process, illustrated in Figure 1. First, preforms were prepared using mask electrochemical micromachining [18]. Then, the sharp edges of the preforms were smoothened by mass transport-limited dissolution. The parameters used for the preforms and dissolution, which are required to create a final sinusoidal topography, were determined using numerical simulations of the process based on the work of West et al. [19]. Images extracted from the simulated process are shown in Figure 1: part (a) to (c) correspond to the first step (i.e. preform creation through mask electrochemical 
micromachining) while part (d) to (f) illustrate the second step (i.e. mass transport limited dissolution of the preforms after removing the masks).
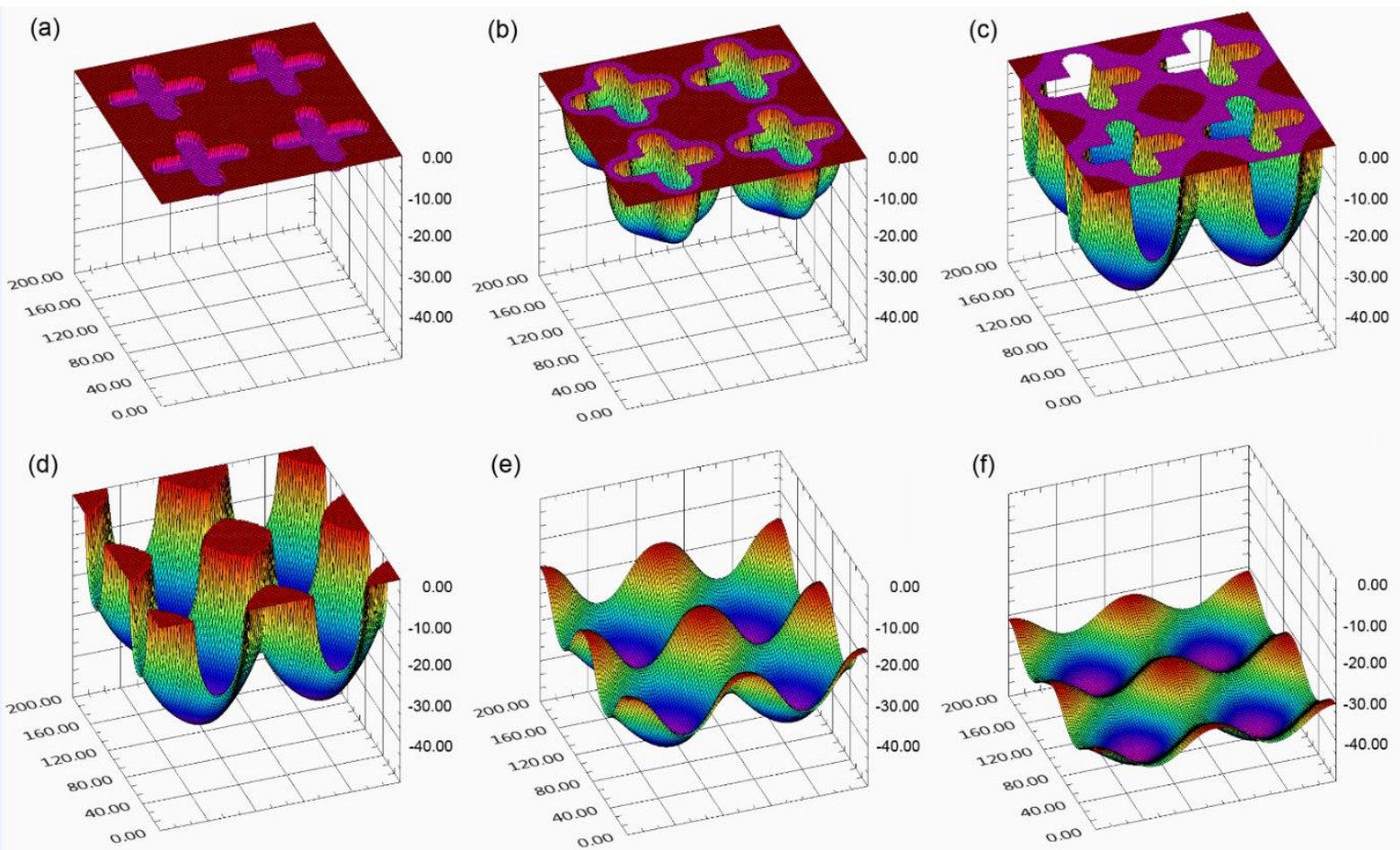

Figure 1 : Images extracted from the simulated two-step process used to obtain sinusoidal surfaces having an amplitude of $10 \mu \mathrm{m}$ and a period of $100 \mu \mathrm{m}:(a)$ to (c) preform creation through mask electrochemical micromachining), (d) to (f) mass transport limited dissolution of preforms after mask removal.

Four three-dimensional sinusoidal surfaces (similar to egg boxes) were produced in AISI 316L stainless steel, which is a common austenitic stainless steel. Table 1 summarizes the main targeted geometric characteristics of the studied surfaces (amplitudes and periods). Figure 2 shows examples of topography measurement of the examined specimens.

\begin{tabular}{|c|c|c|}
\hline Sample name & Period $(\boldsymbol{\mu m})$ & $\begin{array}{c}\text { Peak-to-valley } \\
\text { amplitude }(\boldsymbol{\mu m})\end{array}$ \\
\hline $030 \_03$ & 30 & 3 \\
\hline $100 \_03$ & 100 & 3 \\
\hline 100_10 & 100 & 10 \\
\hline 300_30 & 300 & 30 \\
\hline Table 1 : Main targeted geometric characteristics of the sinusoidal surfaces
\end{tabular}



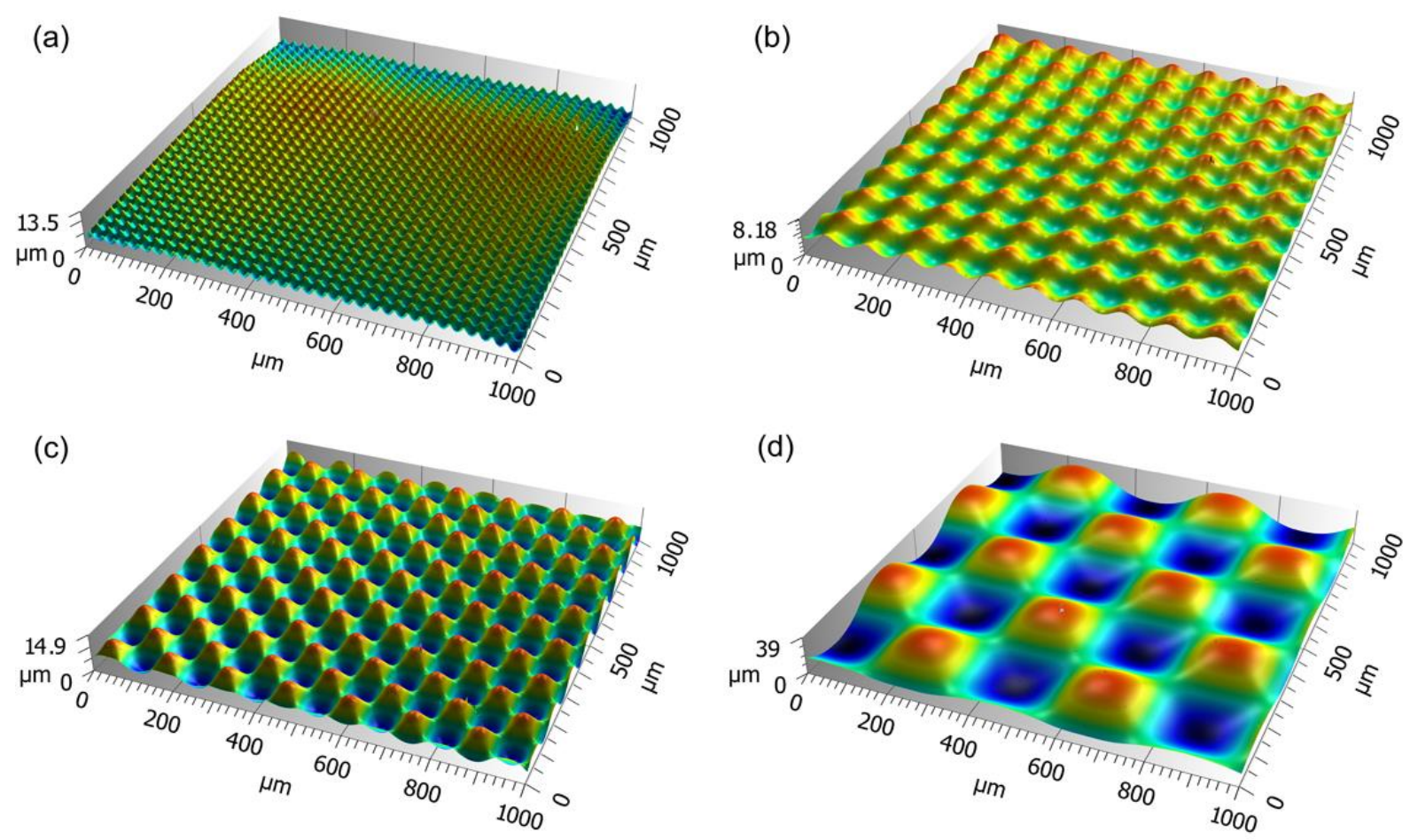

Figure 2 : Example of topography measurements for (a) specimen 030_03, (b) specimen 100_03, (c) specimen 100_10 and (d) specimen 300_30.

\subsection{Measurements}

Topography measurements were performed with a white-light interferometer (Zygo NewView ${ }^{\mathrm{TM}} 7300$, Zygo Corp., CT, USA) with 100x objective. The lateral resolution was equal to $0.22 \mu \mathrm{m}$ and the vertical accuracy was about $1 \mathrm{~nm}$. This objective gave elemental surface measurements of $69.5 \mu \mathrm{m} \times 52.1 \mu \mathrm{m}$. These elementary surfaces were then stitched with an overlapping of $20 \%$ to obtain large measurement areas (1004 $\mu \mathrm{m}$ x $1004 \mu \mathrm{m}$ for 030_03, 100_03 and 100_10 specimens and $1997 \mu \mathrm{m}$ x $1997 \mu \mathrm{m}$ for the specimen called 300_30). Large measurements with high accuracy were required to allow us to easily rotate the areas to correct the sine alignment and to extract areas containing five sine periods for the assessment of the surface quality (waviness, period quality, sine shape quality). Then, non-measured points were filled based on the height of the neighboring points. Finally, the measured areas were rectified using a polynomial of degree 1 to correct any rectitude issues, which are not part of the metrology quantification.

\section{Results}

First, the microroughness on the sinusoidal surfaces was assessed. It was found that the stitched measurements could not be used for this quantification as stitching can introduce local errors in the measurements. Figure 3 illustrates the local defaults introduced by stitching: in part a of this figure, an area of $100 \mu \mathrm{m} \times 100 \mu \mathrm{m}$ was extracted from the measurements of 300_30 while in part $b$, the same area was filtered with a high-pass Gaussian filter with a cut-off of $3 \mu \mathrm{m}$. This filtering enabled us to remove the sine shape to examine the microroughness of the surface. In the example shown in Figure 3.b, the maximum height $S_{z}$ is equal to $0.71 \mu \mathrm{m}$. This value is small but may introduce some error in the determination of the microroughness. 
(a)
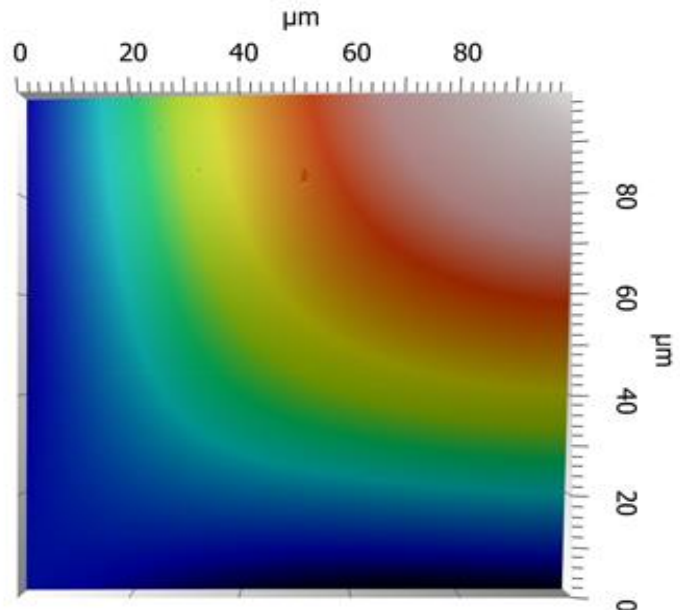

(b)

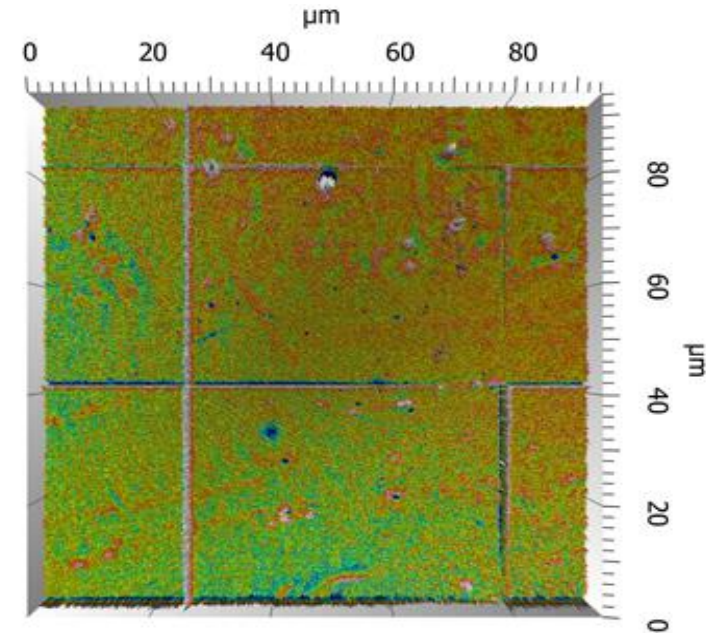

Figure 3: (a) Extraction of an area $100 \mu \mathrm{m} \times 100 \mu \mathrm{m}$ from a measurement of 300_30 and (b) corresponding area filtered with a high-pass Gaussian filter with a cut-off of $3 \mu \mathrm{m}$.

As a consequence, the elemental measurements of $69.5 \mu \mathrm{m} \times 52.1 \mu \mathrm{m}$ were used to assess the microroughness of the surface. To remove the form, a high-pass spline filtering [20] with a cutoff of $5 \mu \mathrm{m}$ was used. Finally, the arithmetic mean deviation $S_{a}$ [21] was computed for each elemental surface. Some elemental measurements were removed because there were outliers or measurement disturbances therefore 4000 elemental surfaces were used for each case. Table 2 shows the average and standard deviations of $S_{a}$ obtained for the four cases, as well as the ratio of the peak-to valley amplitude by the average of $S_{a}$.

\begin{tabular}{|c|c|c|c|}
\hline $\begin{array}{c}\text { Specimen } \\
\text { name }\end{array}$ & Average $\mathbf{S}_{\mathbf{a}}(\mathbf{n m})$ & $\begin{array}{c}\text { Standard deviation } \mathbf{S}_{\mathbf{a}} \\
(\mathbf{n m})\end{array}$ & $\mathbf{A} / \mathbf{S}_{\mathbf{a}}$ \\
\hline $030 \_03$ & 12 & 1 & 261 \\
\hline $100 \_03$ & 1 & 1 & 4286 \\
\hline $100 \_10$ & 1 & 1 & 16667 \\
\hline $300 \_30$ & 1 & 1 & 60000 \\
\hline
\end{tabular}

Table 2: Average and standard deviation of $S_{a}$ computed for each specimen, using elemental surface measurements. The ratios of the peak-to-valley amplitude of the surface by the average $S_{a}$ is also provided.

The values found for the average and standard deviation of $S_{a}$ are very low: The computed values were around $1 \mathrm{~nm}$. Moreover, the ratios of the peak-to-valley amplitude of the surfaces by the average $S_{\mathrm{a}}$ ranged between 261 and 60000 , highlighting the smoothness of the surfaces. To explain the differences of values, examples of microroughness are given in Figure 4 for all the specimens. It can be seen that some pitting took place in specimen 030_03, thus explaining the higher value of the average $S_{\mathrm{a}}$. In Figure $4 \mathrm{~b}$ and c (corresponding to 100_03 and 100_10), the grain boundaries of the metal can be observed. Local holes can also be present and were caused by the process. 


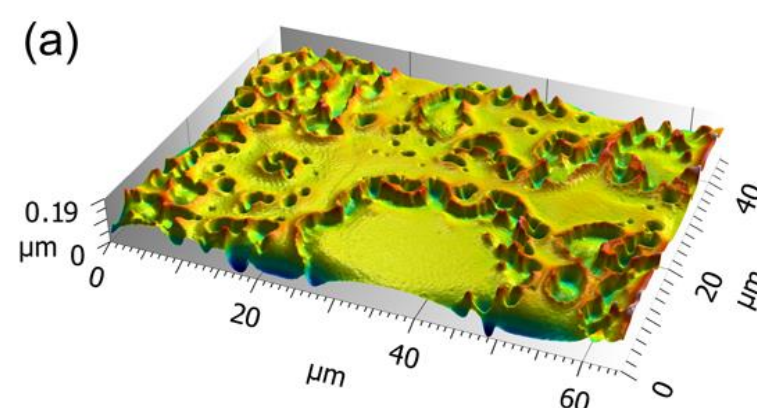

(c)

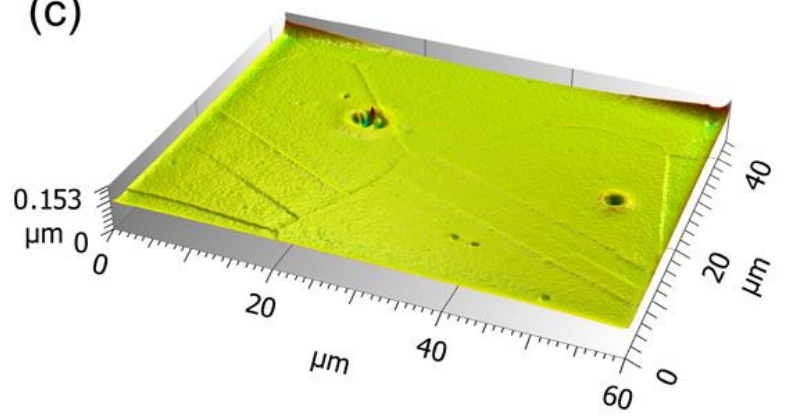

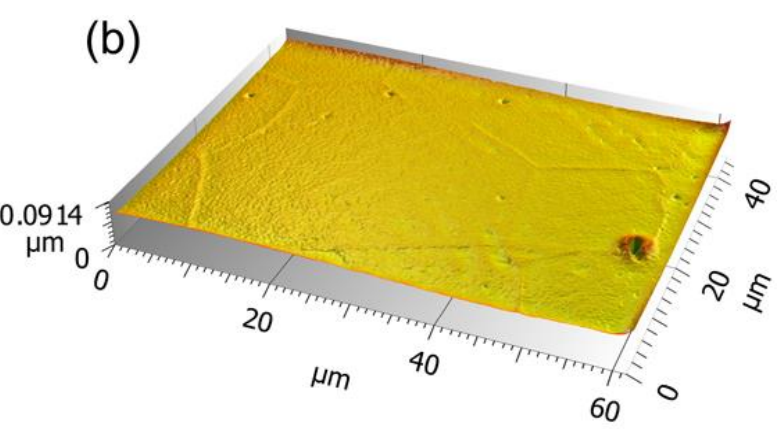

(d)

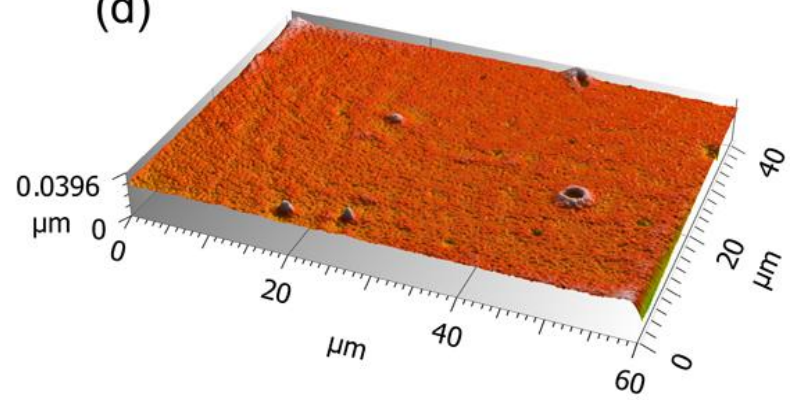

Figure 4: Examples of microroughness for (a) specimen 030_03, (b) specimen 100_03, (c) specimen 100_10 and (d) specimen 300_30.

The waviness of the sinusoidal surfaces was then quantified, using square areas containing $5 \mathrm{x}$ 5 periods. A low-pass Gaussian filter [22] with a cut-off equal to the length of the measurement divided by 1.66 was found to be correct to remove the sine shape. Examples of computed waviness are given in Figure 5. The arithmetic mean deviation $S_{a}$ was computed on each resulting surface. This method was performed five times for each configuration. Table 3 summarizes the average and standard deviations of $S_{a}$ obtained for the four cases, as well as the ratio of the peak-to valley amplitude by the average of $S_{a}$.
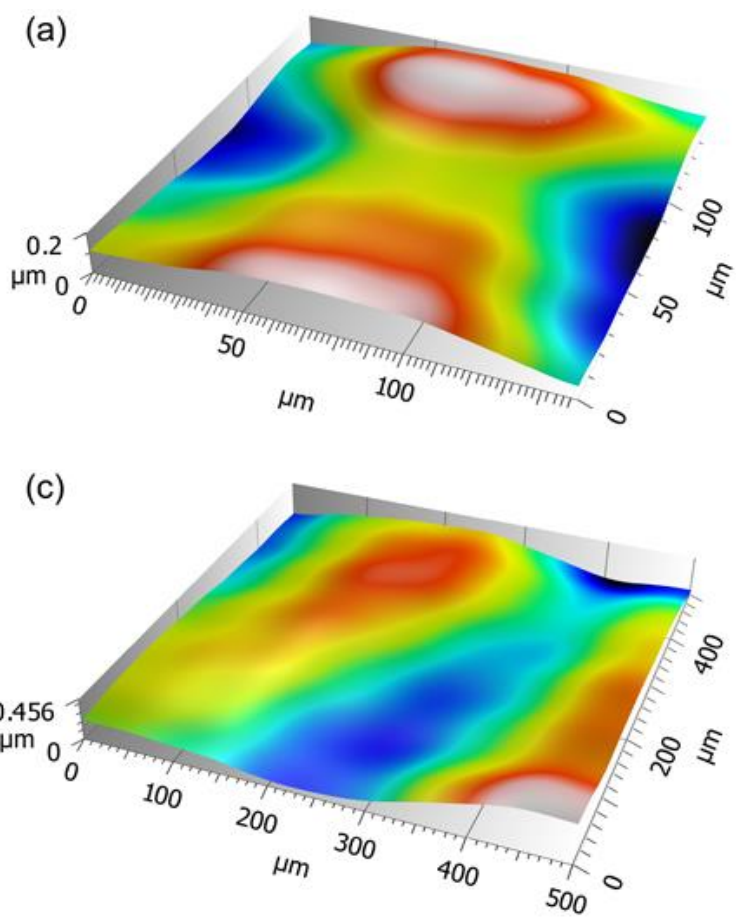

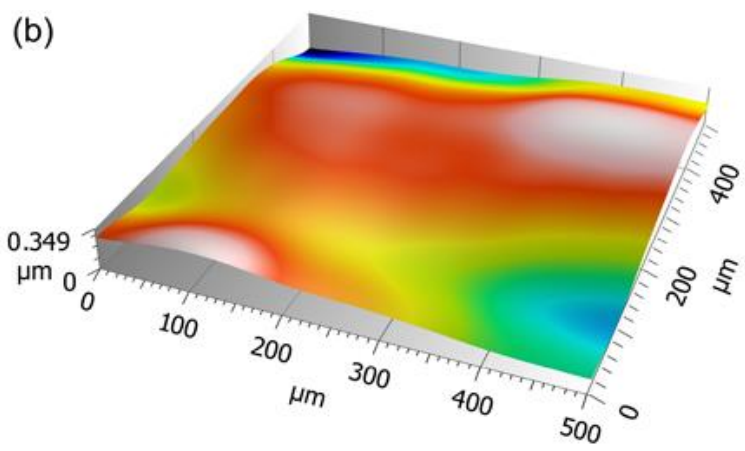

(d)

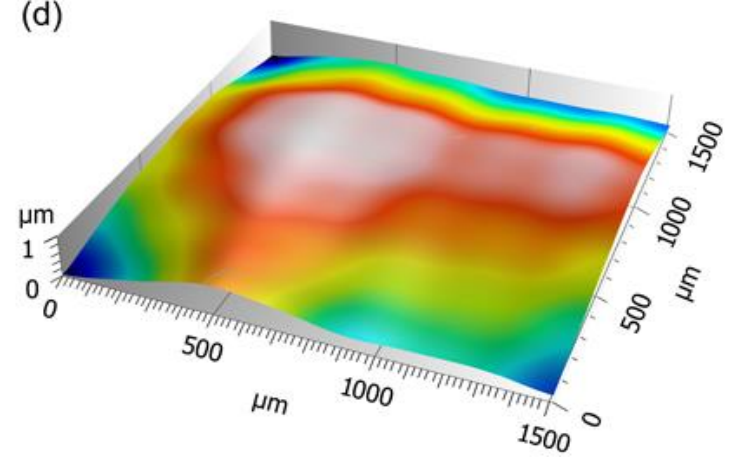

Figure 5: Examples of waviness computed for each specimen. 


\begin{tabular}{|c|c|c|c|c|}
\hline $\begin{array}{c}\text { Specimen } \\
\text { name }\end{array}$ & $\begin{array}{c}\text { Area size } \\
\left(\boldsymbol{\mu m}^{\mathbf{2}}\right)\end{array}$ & $\begin{array}{c}\text { Average } \mathbf{S} \mathbf{a} \\
(\boldsymbol{\mu \mathbf { m } )}\end{array}$ & $\begin{array}{c}\text { Standard deviation } \mathbf{S} \mathbf{a} \\
(\boldsymbol{\mu m})\end{array}$ & $\mathbf{A} / \mathbf{S}_{\mathbf{a}}$ \\
\hline $030 \_03$ & $150 \times 150$ & 0.04 & 0.02 & 70 \\
\hline $100 \_03$ & $500 \times 500$ & 0.04 & 0.01 & 73 \\
\hline $100 \_10$ & $500 \times 500$ & 0.08 & 0.03 & 133 \\
\hline $300 \_30$ & $1510 \times 1510$ & 0.15 & 0.05 & 205 \\
\hline
\end{tabular}

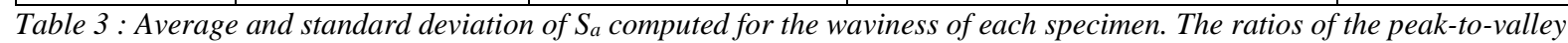
amplitude of the surface by the average Sa is also computed.

Some waviness was detected as the average $S_{a}$ was comprised between $0.04 \mu \mathrm{m}$ and $0.15 \mu \mathrm{m}$. However, the ratios of the peak-to-valley amplitude of the surfaces by the average $S_{a}$ remained large, thus emphasizing the quality of the surfaces obtained with the two-step process. The average $S_{a}$ values were found to be higher with an increase of the amplitude or period. This could be partly explained by an increase of the area size used in the computation. However, specimen 100_03 and 100_10 have both the same area size and the average $S_{a}$ was found to increase with an increase of the amplitude of the sinusoidal shape. New specimens would be required to confirm this trend.

The accuracy of the sine period was assessed using image segmentation: the watershed algorithm [21] allowed us to decompose square areas containing $5 \times 5$ periods into motifs. Then, the minimum pitch between two identified peaks was computed. This method was applied five times per specimen. Figure 6 shows an example of segmentation for a measurement of specimen 100_10. The average results obtained for the pitch are presented in Table 4. The relative error corresponding to the subtraction of the aimed period from the identified pitch, divided by the aimed period was also computed and is shown in Table 4.
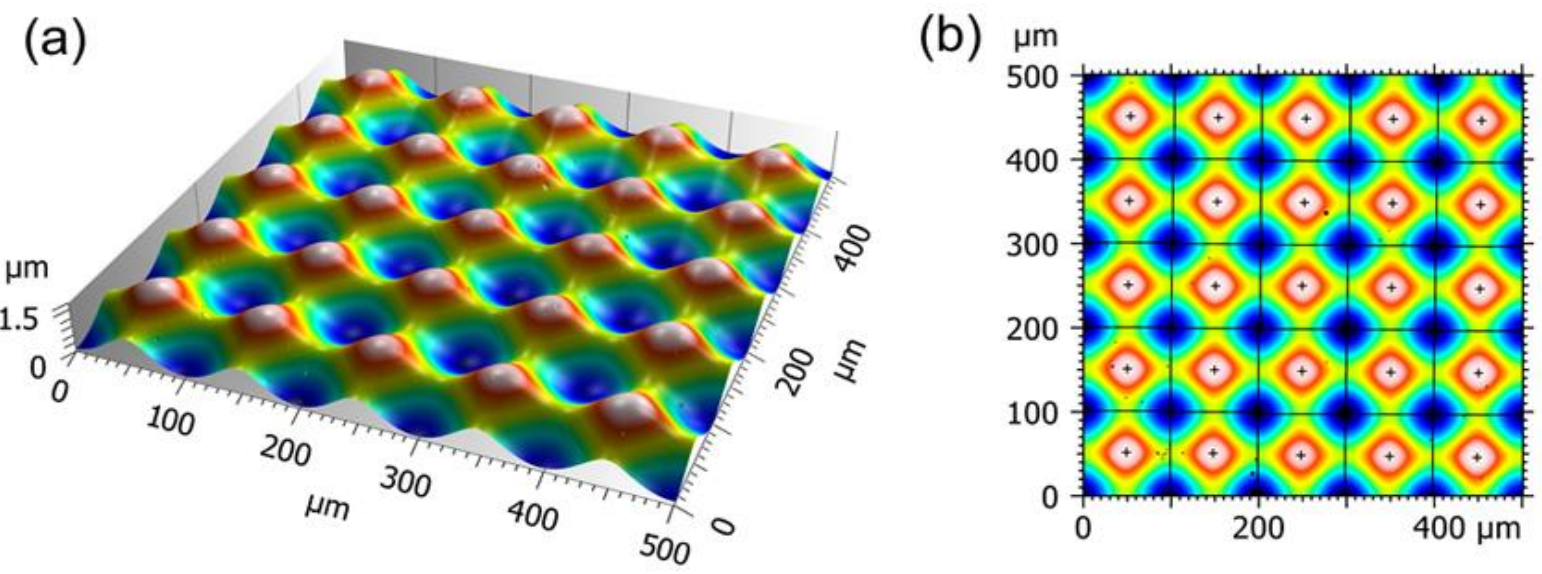

Figure $6:$ (a) Example of a measurement of 100_10 containing $5 \times 5$ periods and $(b)$ the decomposition of this measurement into motifs using the watershed algorithm.

\begin{tabular}{|c|c|c|c|}
\hline Specimen name & $\begin{array}{c}\text { Average minimum } \\
\text { pitch }(\boldsymbol{\mu m})\end{array}$ & $\begin{array}{c}\text { Standard deviation } \\
(\boldsymbol{\mu m})\end{array}$ & Relative error $(\%)$ \\
\hline $030 \_03$ & 29.79 & 0.12 & -0.7 \\
\hline $100 \_03$ & 98.71 & 0.97 & -1.3 \\
\hline $100 \_10$ & 99.61 & 0.48 & -0.4 \\
\hline 300_30 & 299.64 & 0.68 & -0.1 \\
\hline
\end{tabular}

Table 4 : Average and standard deviation of the minimum pitch between two peaks and the relative error, computed for each specimen. 
The identified average minimum pitches were slightly lower than the aimed periods, for all the specimens. Specimen 100_03 showed the maximum relative error. This specimen had the only configuration in which the period-to-amplitude ratio was different from 10. This difference may explain the increased maximum relative error. The minimum relative error was found for the larger motifs i.e. for specimen 300_30. The relative error remained lower than $1.5 \%$ for all the specimens, which highlighted the regularity of the period.

Finally, the regularity of the sine shape was assessed by minimizing the differences of shape between square measurement areas containing 5 x 5 periods and the following mathematical function:

$Z=A\left(\cos \left(\frac{X}{P}+\varphi_{1}\right) * \cos \left(\frac{X}{P}+\varphi_{2}\right)\right)$

where $\mathrm{Z}$ is the height, $\mathrm{X}$ are the in-plane coordinates, $\mathrm{P}$ is a parameter proportional to the period, $\mathrm{A}$ is the amplitude and $\varphi 1, \varphi 2$ are the phases. It should be noted that the chosen mathematical model only contained two main parameters $\mathrm{A}$ and $\mathrm{P}$ as $\varphi 1, \varphi 2$ were only part of the equation to adjust the beginning of the sine shape to the cutting of the sine shape measurements. The choice to use of only two main parameters in the description was made to be "mathematically unfavorable" i.e. it minimized the degrees of freedom in the minimization, thus hardening the quality criteria.

Once the parameters of the mathematical function were identified thanks to a non-linear regression, the quality of the surface shape was quantified through the computation of the residue, which is the standard deviation of the height of the identified mathematical function subtracted by the height of the measured surface. Again, this methodology was applied five times per specimen. Figure 7 shows an example of measured surface, the computed surface obtained with the identification of the parameters and the surface obtained by the subtraction of both surfaces, with which the residue was computed. Table 5 summarizes the results obtained for the computed residues.

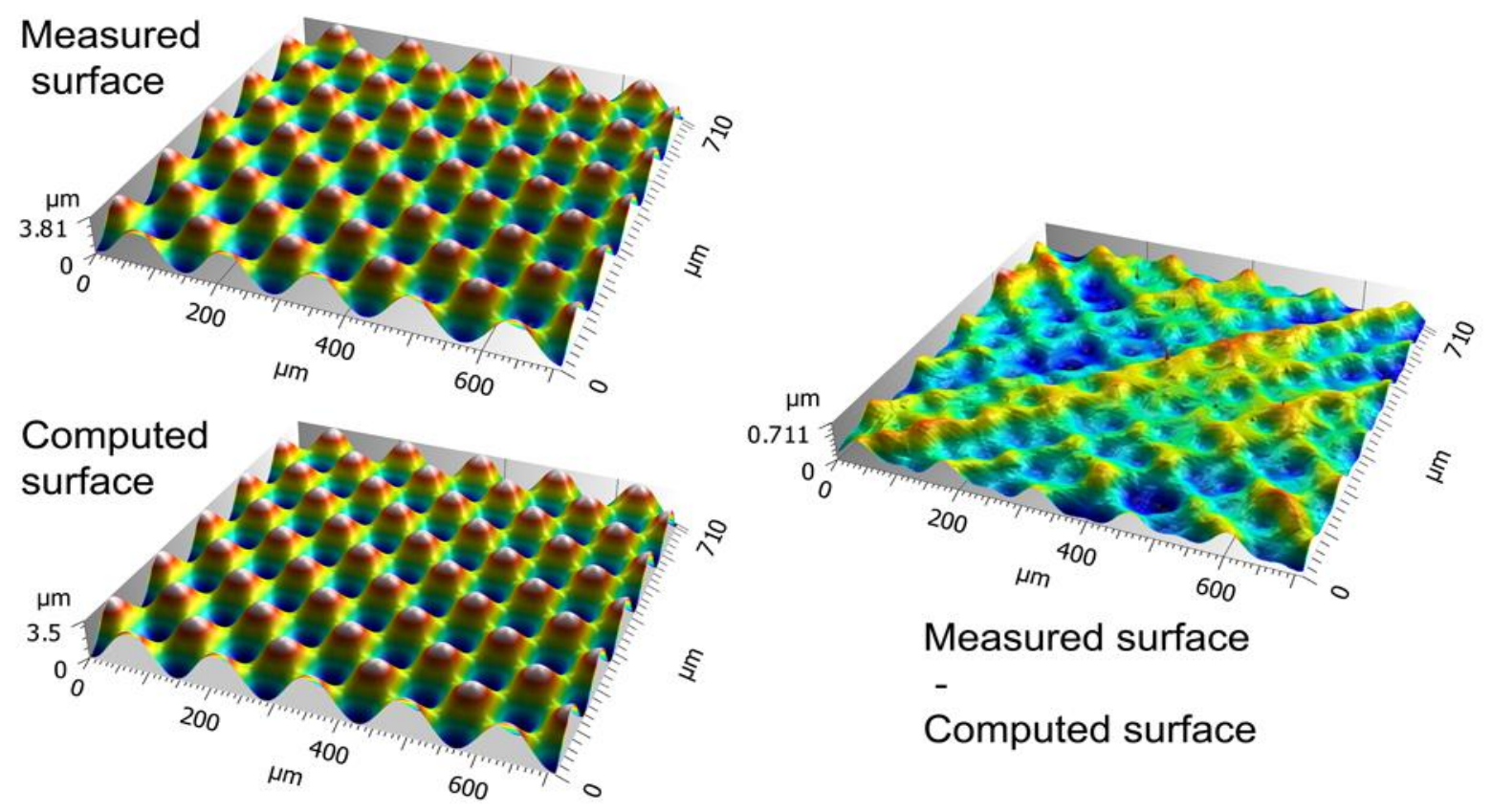


Figure 7: Example of measured surface for 10_03, of the computed surface obtained with the identification of the parameters and of the surface obtained with the subtraction of the computed surface from the measured surface.

\begin{tabular}{|c|c|c|c|}
\hline $\begin{array}{c}\text { Specimen } \\
\text { name }\end{array}$ & $\begin{array}{c}\text { Residue } \\
\text { average }(\boldsymbol{\mu m})\end{array}$ & $\begin{array}{c}\text { Residue standard } \\
\text { deviation }(\boldsymbol{\mu m})\end{array}$ & A/Residue average \\
\hline 030_03 & 0.185 & 0.016 & 16 \\
\hline $100 \_03$ & 0.102 & 0.006 & 29 \\
\hline 100_10 & 0.339 & 0.019 & 39 \\
\hline 300_30 & 0.762 & 0.012 & 39 \\
\hline
\end{tabular}

Table 5: Average and standard deviation of the residue. The ratios of the peak-to-valley amplitude of the surface by the average residue is also computed.

Again, low values were found for the residue average. This result is highlighted by the computation of the ratio of the peak-to-valley amplitude of the surfaces by the residue average: values ranging from 16 to 39 were found. These ratios may seem lower than the ones previously computed, however, the residue average contained all possible errors on the sinusoidal shape. The residue standard deviations were also small thus showing good repeatability of the results.

\section{Discussion}

The analyses of topography measurements showed that the presented three-dimensional surfaces had very good characteristics: low waviness, very low residual micro-roughness on the sine shape and an accurate sine shape with very regular period. Table 6 summarizes the main characteristics of the examined sinusoidal surfaces.

\begin{tabular}{|l|l|l|l|l|}
\hline $\begin{array}{l}\text { Specimen } \\
\text { name }\end{array}$ & $\begin{array}{l}\text { Microroughness: } \mathbf{S} \mathbf{a} \\
(\mathbf{n m})\end{array}$ & $\begin{array}{l}\text { Waviness: } \mathbf{S}_{\mathbf{a}} \\
(\boldsymbol{\mu m})\end{array}$ & $\begin{array}{l}\text { Period relative } \\
\text { error }(\boldsymbol{\%})\end{array}$ & Residue $(\boldsymbol{\mu m})$ \\
\hline $030 \_03$ & $12 \pm 1$ & $0.04 \pm 0.02$ & -0.7 & $0.185 \pm 0.016$ \\
\hline $100 \_03$ & $1 \pm 1$ & $0.04 \pm 0.01$ & -1.3 & $0.102 \pm 0.006$ \\
\hline $100 \_10$ & $1 \pm 1$ & $0.08 \pm 0.03$ & -0.4 & $0.339 \pm 0.019$ \\
\hline 300_30 & $1 \pm 1$ & $0.15 \pm 0.05$ & -0.1 & $0.762 \pm 0.012$ \\
\hline
\end{tabular}

Table 6: Summary of the characteristics of the examined sinusoidal surfaces.

Such three-dimensional sinusoidal surfaces, at the microscale, are rarely reported in the literature. Only three studies showing three-dimensional sinusoidal surfaces having comparable microscale motifs were identified in the literature: the corresponding characteristics of the surfaces are listed in Table 7.

\begin{tabular}{|c|c|c|c|}
\hline Reference & Process & Peak-to-valley amplitude & Period \\
\hline \multirow[t]{4}{*}{$\begin{array}{l}\text { Chen et al. } \\
\text { [7] }\end{array}$} & \multirow[t]{4}{*}{$\begin{array}{l}\text { Fast tool servo } \\
\text { (diamond machining) }\end{array}$} & $\begin{array}{l}2 \mu \mathrm{m} \text { (measured to be } \\
1.96 \pm 0.045 \mu \mathrm{m})\end{array}$ & $150 \mu \mathrm{m}$ \\
\hline & & $\begin{array}{l}2 \mu \mathrm{m} \quad(\text { measured to be } \\
1.93 \pm 0.060 \mu \mathrm{m})\end{array}$ & $300 \mu \mathrm{m}$ \\
\hline & & $\begin{array}{l}0.6 \mu \mathrm{m} \text { (measured to be } \\
0.58 \pm 0.035 \mu \mathrm{m})\end{array}$ & $450 \mu \mathrm{m}$ \\
\hline & & $\begin{array}{l}22.06 \pm 0.7 \mu \mathrm{m}(\text { measured to } \\
\text { be } 21.95 \pm 0.11 \mu \mathrm{m})\end{array}$ & $\begin{array}{l}550 \mu \mathrm{m} \text { (measured to } \\
\text { be } 547.64 \pm 1.15 \mu \mathrm{m} \\
\text { in the X-direction } \\
\text { and } 548.97 \pm 0.96 \mu \mathrm{m} \\
\text { in the Y-direction) }\end{array}$ \\
\hline
\end{tabular}




\begin{tabular}{|l|l|l|l|}
\hline $\begin{array}{l}\text { Shimizu et } \\
\text { al. [23] }\end{array}$ & $\begin{array}{l}\text { Fast tool servo } \\
\text { (diamond machining) }\end{array}$ & $0.4 \mu \mathrm{m}$ & $10 \mu \mathrm{m}$ \\
\hline $\begin{array}{l}\text { Gao et al. } \\
{[24]}\end{array}$ & $\begin{array}{l}\text { Fast tool servo } \\
\text { (diamond machining) }\end{array}$ & $0.1 \mu \mathrm{m}$ & $100 \mu \mathrm{m}$ \\
\hline
\end{tabular}

Table 7: Characteristics of the three-dimensional sinusoidal surfaces of the literature.

First, it should be noted that the period/amplitude ratios were either equal to 10 or 33 for the surfaces presented in this paper while this ratio is between 25 and 750 for [7] and is equal to 25 and 1000 for [23] and [24], respectively.

Chen et al. [7] compared the characteristics of the surface given by the manufacturer to the measurements made with scanning tunneling microscope. Deviations were found to be small for amplitude and period. As an example for the aimed period of $550 \mu \mathrm{m}$, they measured a period equal to $547.64 \pm 1.15 \mu \mathrm{m}$ in the $\mathrm{X}$-direction and $548.97 \pm 0.96 \mu \mathrm{m}$ in the $\mathrm{Y}$-direction, thus giving relative errors of $-0.43 \%$ and $-0.19 \%$, respectively. These errors are of the same order of magnitude as the sinusoidal surfaces examined in this paper. The surface measurements of Chen et al. [7] are shown to be around $1000 \mu \mathrm{m}$ x $1000 \mu \mathrm{m}$ thus indicating low waviness. However, no comments were made on possible micro-roughness. A closer look at the given figures show local defects on the summits thus possibly indicating micro-roughness on the sinusoidal shape. Shimizu et al. [23] used a three-dimensional sinusoidal surface to compare the results given by three devices: a confocal microscope, a white-light interferometer and an atomic force microscope. The different devices gave similar results for pitch and amplitude, confirming the dimensions given by the manufacturer. However, the use of two-dimensional discrete Fourier transform for the analysis of the measurements indicated a form error caused by the round geometry of the tool. Gao et al. [24] gave similar results but showed that tool radius compensation was possible: the amplitudes of the error caused by the round-tip of the tool were reduced to several nanometers.

The previous comparisons remained limited but enabled us to identify a possible competing process: the use of a fast tool servo in diamond machining. This process produced sinusoidal surfaces having very good shape qualities. However, machining of metallic materials probably induced local strain-hardening or added residual stresses. The two-step process used to obtain the sinusoidal surfaces described in this paper did not induce any changes of sub-surface mechanical properties. This is a real asset for the examination of the link between surface morphology and functionality because it guarantees a decoupling of the examined effects. Topography effects are too often coupled with local changes of sub-surface mechanical properties thus introducing biases or errors in the results. As an example, this decoupling is particularly important in contact or wear study. Finally, through the characterization of sinusoidal surfaces, we were able to detect stitching errors in the measurements. These errors were minor at large scales but could have introduced some bias at the microscale when determining the microroughness. It seems that the quality of the examined sinusoidal surfaces i.e. their very good signal-to-noise ratio led to difficulties in local fitting of the elementary surfaces thus introducing stitching errors.

\section{Conclusion}

The topography of three-dimensional sinusoidal surfaces obtained with a two-step process were thoroughly characterized. It was shown that the two-step process consisting of electrochemical 
machining followed by mass transport-limited dissolution produced surfaces having very low microroughness: the $S_{a}$ values used to quantify the microroughness ranged between $1 \mathrm{~nm}$ and $12 \mathrm{~nm}$. The largest value was found to be caused by local pitting in a given specimen. The waviness of the surfaces was also quantified using the $S_{\text {a }}$ parameter and the largest value was found to be equal to $0.15 \mu \mathrm{m}$. Higher values of waviness were noted with an increase of the amplitude or period of the sinusoidal surfaces but the production of other surfaces would be required to confirm this trend. The maximum relative error computed for the period was equal to $-1.3 \%$ and was identified for the configuration having a period-to-amplitude ratio different from 10. Finally, the quality of the sinusoidal shape was assessed by minimizing the difference of height between the measurements and a corresponding mathematical function. Again, the computed residues were very small. A comparison of these results with the literature was difficult as the conditions or chosen data did not exactly match. The use of a fast tool servo in diamond machining was found to produce three-dimensional sinusoidal surfaces showing very good characteristics too. However, mechanical machining usually introduces local changes in the sub-surface properties. The two-step process used to build the sinusoidal surfaces examined in this paper avoids any local changes of mechanical properties. This is a real asset for the decoupling of the effects of the surface topography from the effects of residual stresses when examining a given functionality. Such decoupling would be particularly useful in the examination of contact and wear. Other perspectives of use can be mentioned for these surfaces:

- the addition of controlled microtexturation on the sinusoidal shape. This addition could help decoupling the effects of topography at different scales (sine shape and microtexture scales). Different fields could be interested by such applications: mechanics, biology, optics...

- the addition of a thin film could be used to examine the influence of the topography of the interface on the adhesion of the film.

\section{References}

[1] K.H. Song, S.J. Park, D.S. Kim, J. Doh, Sinusoidal wavy surfaces for curvature-guided migration of T lymphocytes, Biomaterials. 51 (2015) 151-160. https://doi.org/http://dx.doi.org/10.1016/j.biomaterials.2015.01.071.

[2] L. Skedung, M. Arvidsson, J.Y. Chung, C.M. Stafford, B. Berglund, M.W. Rutland, Feeling Small: Exploring the Tactile Perception Limits, Sci. Rep. 3 (2013) 2617. https://doi.org/10.1038/srep02617http://www.nature.com/articles/srep02617\#suppleme ntary-information.

[3] C. Bukowsky, J.M. Torres, B.D. Vogt, Slip-stick wetting and large contact angle hysteresis on wrinkled surfaces, J. Colloid Interface Sci. 354 (2011) 825-831. https://doi.org/http://dx.doi.org/10.1016/j.jcis.2010.11.034.

[4] Z. Yang, Q. Chen, A.E. Elbanna, S. Kim, Transfer printing enabled soft composite films for tunable surface topography, Extrem. Mech. Lett. (n.d.). https://doi.org/http://dx.doi.org/10.1016/j.eml.2016.01.001.

[5] R. Antos, I. Ohlidal, D. Franta, P. Klapetek, J. Mistrik, T. Yamaguchi, S. Visnovsky, Spectroscopic ellipsometry on sinusoidal surface-relief gratings, Appl. Surf. Sci. 244 (2005) 221-224. https://doi.org/http://dx.doi.org/10.1016/j.apsusc.2004.09.142. 
[6] H. Lu, D.-W. Lee, S.-M. Lee, J.-W. Park, Diamond machining of sinusoidal grid surface using fast tool servo system for fabrication of hydrophobic surface, Trans. Nonferrous Met. Soc. China. 22, Supple (2012) s787-s792. https://doi.org/http://dx.doi.org/10.1016/S1003-6326(12)61805-6.

[7] Y.-L. Chen, W.-L. Zhu, S. Yang, B.-F. Ju, Y. Ge, Large-area profile measurement of sinusoidal freeform surfaces using a new prototype scanning tunneling microscopy, Precis. Eng. 38 (2014) 414-420. https://doi.org/http://dx.doi.org/10.1016/j.precisioneng.2013.12.008.

[8] A. Temmler, N. Pirch, J. Luo, J.H. Schleifenbaum, C.L. Häfner, Numerical and experimental investigation on formation of surface structures in laser remelting for additive-manufactured Inconel 718, Surf. Coatings Technol. 403 (2020) 126370. https://doi.org/10.1016/j.surfcoat.2020.126370.

[9] P. Rougerie, L. Pieuchot, R.S. dos Santos, J. Marteau, M. Bigerelle, P.F. Chauvy, M. Farina, K. Anselme, Topographical curvature is sufficient to control epithelium elongation, Sci. Rep. 10 (2020) 1-14. https://doi.org/10.1038/s41598-020-70907-0.

[10] C. Fedele, E. Mäntylä, B. Belardi, T. Hamkins-Indik, S. Cavalli, P.A. Netti, D.A. Fletcher, S. Nymark, A. Priimagi, T.O. Ihalainen, Azobenzene-based sinusoidal surface topography drives focal adhesion confinement and guides collective migration of epithelial cells, Sci. Rep. 10 (2020) 1-15. https://doi.org/10.1038/s41598-020-71567w.

[11] R. Leach, H. Haitjema, R. Su, A. Thompson, Metrological characteristics for the calibration of surface topography measuring instruments: A review, in: Meas. Sci. Technol., IOP Publishing Ltd, 2020: p. 032001. https://doi.org/10.1088/13616501/abb54f.

[12] D. Hu, G.G. Adams, Adhesion of a micro-/nano- beam/plate to a sinusoidal/grooved surface, Int. J. Solids Struct. 99 (2016) 40-47. https://doi.org/10.1016/j.ijsolstr.2016.08.008.

[13] G. Xie, S.D. Iwnicki, Calculation of wear on a corrugated rail using a threedimensional contact model, Wear. 265 (2008) 1238-1248. https://doi.org/10.1016/j.wear.2008.01.026.

[14] Z. Peng, S. Chen, Peeling behavior of a thin-film on a corrugated surface, Int. J. Solids Struct. 60 (2015) 60-65. https://doi.org/10.1016/j.ijsolstr.2015.02.003.

[15] N.F. Declercq, J. Degrieck, R. Briers, O. Leroy, Diffraction of homogeneous and inhomogeneous plane waves on a doubly corrugated liquid/solid interface, Ultrasonics. 43 (2005) 605-618. https://doi.org/10.1016/j.ultras.2005.03.008.

[16] T. Thenard, A. Catapano, M. Mesnard, R. Allena, A Cellular Potts energy-based approach to analyse the influence of the surface topography on single cell motility, J. Theor. Biol. 509 (2021) 110487. https://doi.org/10.1016/j.jtbi.2020.110487.

[17] L. Pieuchot, J. Marteau, A. Guignandon, T. Dos Santos, I. Brigaud, P.-F. Chauvy, T. Cloatre, A. Ponche, T. Petithory, P. Rougerie, M. Vassaux, J.-L. Milan, N. Tusamda Wakhloo, A. Spangenberg, M. Bigerelle, K. Anselme, Curvotaxis directs cell migration through cell-scale curvature landscapes, Nat. Commun. 9 (2018) 3995. 
https://doi.org/10.1038/s41467-018-06494-6.

[18] D. Landolt, P.-F. Chauvy, O. Zinger, Electrochemical micromachining, polishing and surface structuring of metals: fundamental aspects and new developments, Electrochim. Acta. 48 (2003) 3185-3201. https://doi.org/10.1016/S0013-4686(03)00368-2.

[19] A.C. West, C. Madore, M. Matlosz, D. Landolt, Shape changes during through-mask electrochemical micromachining of thin metal films, J. Electrochem. Soc. 139 (1992) 499-506.

[20] I. Standard, ISO 16610-62 - Geometrical product specifications - Filtration - Part 62: Linear areal filter - Spline filter, (n.d.). https://www.iso.org/standard/79790.html.

[21] I.O. for Standardization, ISO standard 25178, (2012).

[22] I. Standard, ISO 16610-61 Geometrical product specification - filtration - Part 61: Linear areal filters - Gaussian filters, (2015).

[23] Y. Shimizu, S. Osaw, T. Meguro, W. Lu, W. Gao, Surface characterization of a diamond turned XY sinusoidal grating, Procedia Eng. 19 (2011) 337-342. https://doi.org/http://dx.doi.org/10.1016/j.proeng.2011.11.122.

[24] W. Gao, T. Araki, S. Kiyono, Y. Okazaki, M. Yamanaka, Precision nano-fabrication and evaluation of a large area sinusoidal grid surface for a surface encoder, Precis. Eng. 27 (2003) 289-298. https://doi.org/10.1016/S0141-6359(03)00028-X. 